\title{
Interrelations of risk factors and low back pain in scaffolders
}

\author{
L A M Elders, A Burdorf
}

\begin{abstract}
Objectives-To assess with a cross sectional study the interrelations between physical, psychosocial, and individual risk factors and different end points of low back pain.

Methods-In total, 229 scaffolders and 59 supervisors completed a questionnaire about manual handling of materials, awkward back posture, strenuous arm position, perceived exertion, psychosocial load, need for recovery, and general health. Physical load at the worksite was also measured with many frequent observations. Interrelations between risk factors and their relation with four end points of low back pain were investigated.
\end{abstract}

Results-Interrelations were strong among self reported determinants of physical load but showed an inverted trend for both age and total working experience, which could indicate the presence of a healthy worker effect. Weak relations existed between variables of psychosocial and physical load. The multivariate analyses showed a significant relation between high manual handling of materials, moderate perceived general health, high job demands, and low back pain in the past 12 months. Chronic low back pain was significantly correlated with high perceived exertion and moderate perceived general health. Severe low back pain was significantly correlated with awkward back postures, high need for recovery, and high job demands. Finally, low back pain with perceived disability was significantly related to strenuous shoulder positions and moderate perceived general health. All end points of low back pain were consistently associated with physical load whereas psychosocial aspects showed a more diverse pattern. Conclusions-The findings of this study suggest that work related risk factors may vary according to different definitions of low back pain. Distinct patterns of risk factors might enhance different expressions of it. Scaffolders are a group at high risk of developing persistent forms of low back pain.

(Occup Environ Med 2001;58:597-603)

Keywords: interrelations; low back pain; risk factors

Occupational Health Service, Maetis arbo Rotterdam

L A M Elders

Correspondence to: Dr L A $M$ Elders

elders@mgz.fgg.eur.nl

Accepted 17 April 2001

Musculoskeletal disorders are a main source of morbidity in many industrialised countries. In 1991, the costs of low back pain in the Netherlands was estimated to be $\$ 4.6$ billion or $1.7 \%$ of the Gross National Product. ${ }^{1}$ In various working populations the attributable fraction of physical load in the occurrence of back disorders varied between $11 \%$ and $58 \% .^{2}$ Despite the extensive number of studies on work related risk factors the interactions of these risk factors in the multifactorial aetiology of low back pain is not well understood. ${ }^{3}$

There is ample evidence for a strong association with physical risk factors - such as manual handling of materials, heavy physical work, frequent bending and twisting, lifting, and forceful movements. ${ }^{4}$ By contrast, there is conflicting evidence for psychosocial risk factors associated with low back pain. A combination of low social support, low job control, high psychological demands, and high perceived work load may cause psychosocial job strain and increase the prevalence of low back pain. ${ }^{6}$ As to individual variables such as age, sex, and physical fitness there is no clear consensus to what extent they are related to low back pain. ${ }^{7}$ Methods to assess the influence of independent risk factors on the presence of low back pain tend to neglect the importance of interrelations between risk factors. Physical, psychosocial, and individual risk factors coexist, are interrelated, and can potentially interact with each other at every stage and phase of low back pain. They are also dynamic modifiers of it as a result of their continuous alteration and changing presence. ${ }^{8}$ There are few studies that in the same occupational group have considered simultaneously physical and psychosocial workload. ${ }^{2}$ This stresses the importance of adopting a broader approach for research on risk factors for low back pain. ${ }^{9}$

Apart from the need to assess exposure to the broad array of potential risk factors, it has also been argued that distinguishing low back pain from more severe, chronic, and disabling conditions is essential for both prognosis and aetiology. ${ }^{10}{ }^{11}$ Setting different end points of low back pain, which can easily coexist in the same person, means anticipating the variability and impact of interrelated risk factors. Each set of risk factors causes a different reaction in a certain time window of a subject's work history and different jobs represent different patterns of risk factors. ${ }^{511}$ As a consequence, information about employment history and working experience are crucial to interpret data on various end points of low back pain. Knowledge of the interrelations between risk factors associated with distinct end points of low back pain might enhance intervention programmes aimed at both worker and workplace.

To our knowledge, there are hardly any studies assessing the interrelations among physical and psychosocial risk factors as well as their relations to various end points of low back pain 
in the study population. Therefore, we conducted a study to $(a)$ determine the interrelations among physical, psychosocial, and individual risk factors, and $(b)$ evaluate the effect of these risk factors on the occurrence of low back pain. The primary goal of this study is to provide information about specific risk factors related to various end points of low back pain in a population who performed heavy physical work.

\section{Subjects and methods}

SUBJECTS

Subjects were selected from a scaffolding company and divided into two occupational groups: (a) scaffolders, scaffolders in training, and scaffolders-porters, and $(b)$ foremen, (assistant) managers, area managers, district managers, auditors, and technical office staff. The principal tasks of scaffolders are erecting and taking down large scale scaffolds. During these tasks manual handling of materials is one of the most dominant activities due to manual lifting, lowering, and carrying of heavy materials such as scaffolding poles and boards, guard rails, and ladders. In total, 337 subjects were invited to participate in this study.

METHOD FOR ASSESSING POSTURAL LOAD

Postural load was assessed by gaining information about awkward postures, strenuous movements, and manual handling of materials. An instant interval sampling method was used for identifying awkward back postures (bent and twisted between $0^{\circ}-20^{\circ}, 20^{\circ}-45^{\circ}$, and $>45^{\circ}$ ), raising one or two arms above shoulder level, and performing manual handling of materials such as lifting and carrying. The forces applied on loads were measured and manual handling of materials with weights below $5 \mathrm{~kg}$ were not taken into consideration, thereby excluding the frequent handling of tools and other equipment.

Observations were made at the workplace every 30 seconds during two separate periods of 30 minutes within 1 working day. Thus, 120 observations were collected for each worker. In total, about 7200 observations were recorded for the scaffolders $(n=60)$, and 2400 observations for supervisors $(n=20)$. Random samples of workers were selected for the observations, stratified by type of scaffolding material and type of worksite, to reflect the general working conditions of the population under study.

\section{QUESTIONNAIRE}

A questionnaire was used to collect personal data, details about the respondent's job and employment history, health, leisure time, and the presence or absence of symptoms of low back pain. The questionnaire was administered in the period June 1998 to September 1998. If necessary, a Turkish questionnaire was administered, either self administered or by interview. Low back pain was defined as pain which had continued for at least a few hours during the past 12 months. Furthermore, pain was rated on a scale according to Von Korff, ranging from 0 to $10 .{ }^{12}$ Four end points of low back pain were defined: (a) low back pain in the past 12 months referred to at least one episode of low back pain in the past 12 months for at least a few hours, $(b)$ chronic low back pain in the past 12 months referred to low back pain which was present almost every day in the preceding 12 months with a minimal presence for at least 3 months, (c) severe low back pain in the past 12 months defined as those subjects with low back pain in the past year exceeding the pain intensity score of 50 according to the Von Korff scheme for grading severity of chronic pain, and $(d)$ low back pain and perceived disability in the past 12 months defined as the subjects who exceeded the disability score of 50 according to the Von Korff scheme for grading disability. The last three definitions are subgroups of the low back pain 12 month prevalence. These definitions are not mutually exclusive as chronicity, severity, and disability may overlap. Both severity and disability are based on a 12 month recall period and as such an expression of the severity and perceived disability during this total recall period.

The questionnaire on musculoskeletal disorders was derived from the standard Nordic questionnaire, which has been proved to be a valid instrument for collecting information on the nature, duration (days), and frequency (occurrences per month) of symptoms. ${ }^{13}$

The questionnaire administered in our study collected data on physical, psychosocial, and individual risk factors. Questions on physical work load concerned manual handling of materials such as lifting and carrying heavy loads, awkward working postures in which the back is bent or twisted, and strenuous arm positions such as working with hands above shoulder level. A four point scale was used with ratings "seldom or never", "now and then", "often", and "always" during a normal working day. The answers often and always were classified as high exposure. The study subjects also rated their perceived exertion on a Borg scale ranging from 6 (very light) to 20 (very heavy), with a score of 16 or higher regarded as high perceived exertion. ${ }^{14}$

The questions on psychosocial aspects were derived from the Karasek model. ${ }^{15}$ In this model subjects are supposedly at risk when experiencing high job demands and low job control. Job demands were measured by 11 questions with a four point scale, yielding a sum score for high work demands. The questions on work demands related to working fast, working hard, excessive work, insufficient time to complete the work, and conflicting demands. Low job control was measured by six questions on skills and 11 questions on authority to make decisions. These questions pertained to aspects such as required skills, task variety, learning new things, and amount of repetitive work. Workers at risk (high demands and low control) were classified using the median scores from the job demands and job control sum scores.

Information on individual risk factors such as age, height, and weight was also derived from the standard Nordic questionnaire as well 
Table 1 Presence of self reported risk factors of low back pain among scaffolders and supervisors

\begin{tabular}{|c|c|c|c|c|}
\hline & \multicolumn{2}{|c|}{$\begin{array}{l}\text { Scaffolders } \\
(n=221)\end{array}$} & \multicolumn{2}{|c|}{$\begin{array}{l}\text { Supervisors } \\
(n=66)\end{array}$} \\
\hline & $n$ & $\%$ & $n$ & $\%$ \\
\hline \multicolumn{5}{|l|}{ Physical load: } \\
\hline $\begin{array}{l}\text { High manual handling of } \\
\text { materials }\end{array}$ & 145 & 66 & 10 & 15 \\
\hline High awkward back posture ${ }^{\star}$ & 129 & 58 & 5 & 8 \\
\hline $\begin{array}{l}\text { High strenuous arm } \\
\text { positions }\end{array}$ & 158 & 71 & 6 & 9 \\
\hline High perceived exertion ${ }^{\star}$ & 163 & 74 & 13 & 20 \\
\hline \multicolumn{5}{|l|}{ Psychosocial load: } \\
\hline $\begin{array}{l}\text { High demand and low job } \\
\text { control }^{\star}\end{array}$ & 65 & 29 & 6 & 9 \\
\hline \multicolumn{5}{|l|}{ Perceived general health: } \\
\hline Need for recovery ${ }^{\star}$ & 115 & 52 & 19 & 29 \\
\hline Moderate general health ${ }^{\star}$ & 89 & 40 & 16 & 24 \\
\hline
\end{tabular}

as information about work history. In the questionnaire two measures of health were included. The first health measure represented short term effects of a day at work, expressed by 11 questions on need for recovery, which considered such aspects as tiredness after work, fatigue, lack of concentration, putting interest in other people, the ability to recover from work, and the influence on work performance. ${ }^{16}$ Finally, perceived general health was measured by 13 dichotomised questions about the workers' health representing the actual health situation and was rated according to the VOEG scale with a good internal scale reliability (Cronbach's $\alpha=0.86$ ) and test-retest reliability (Pearson's $r=0.76) .{ }^{17}$ For both general health end points a sum score was calculated and subjects with a score above the median value were considered to have a high need for recovery and a moderate perceived general health.

STATISTICAL ANALYSIS

In the statistical analyses differences between continuous variables were tested with the unpaired Student $t$ test or Mann-Whitney $U$ test in the case of skewed distributions. The differences between frequencies of categorical variables were tested with the $\chi^{2}$ test. The Spearman rank correlation coefficient $(\theta)$ was used as a measure of association between physical load, psychosocial load, and perceived health whereby the underlying ordinal scales have been used. A generalised log linear model with binominal distribution was used to present associations between work related risk factors and low back pain. Prevalence ratios (PRs) were estimated as a measure of association. The PR is a better approximation of the relative risk than the often used odds ratio in situations where the disease prevalence is high. ${ }^{18}$ As age seems strongly to influence the probability of musculoskeletal symptoms such as back pain, it was included in each logistic model, regardless of the level of significance. For the initial selection of variables in multivariate models a significance level of $p<0.10$ was used. All self reported risk factors presented in table 1 were investigated as well as all relevant individual characteristics and work history aspects. In the final multivariate models only variables with a $p$ value below 0.05 were retained. The statistical analysis was executed with the SAS computer package.

\section{Results}

INDIVIDUAL CHARACTERISTICS AND WORKING EXPERIENCE

Of the 337 workers, 288 completed the interview, yielding an overall response of $85 \%$. No difference in response was found between the 229 scaffolders and 59 supervisors. Age was the only individual characteristic to show a difference between the two occupational groups. The scaffolders were on average 6.8 years younger than the supervisors, respectively 34.5 and 41.2 years. Clear differences were found in work history. On average, the total working experience in years among scaffolders was lower than among supervisors, respectively 15.4 and 24.0 years. The supervisors also had worked more years with the current company (17.3 versus 11.2) but were employed for 5 years less in the current job (6.4 versus 11.3 years) than the scaffolders.

\section{PHYSICAL LOAD, PSYCHOSOCIAL LOAD, AND} PERCEIVED HEALTH

Scaffolders experienced a significantly higher physical load than did the supervisors (table 1). Self reported manual handling of materials showed an inverted trend with age $(\leqslant 30$ years $68.4 \%, 30-40$ years $52.5 \%,>40$ years $39 \%$ ) and total working experience in current company ( $\leqslant 6$ years $61.5 \%, 6-13$ years: $57.4 \%$, $>14$ years $41.1 \%$ ). There was also an inverted trend for self reported awkward back postures with age $(\leqslant 30$ years $52.6 \%, 30-40$ years $48.3 \%,>40$ years $36.3 \%$ ) and total working experience in current company ( $\leqslant 6$ years $52.9 \%, 6-13$ years $49.5 \%,>14$ years $35.3 \%$ ). Furthermore, an inverted trend was present for self reported strenuous arm positions with age ( $\leqslant 30$ years $63.1 \%, 30-40$ years $59.3 \%,>40$ years $44.1 \%)$ and total working experience in current company ( $\leqslant 6$ years $68.3 \%, 6-13$ years $57.4 \%,>14$ years $41.2 \%)$.

Table 2 Comparison of the measurements of exposure to risk factors of low back pain in present working conditions of scaffolders and supervisors

\begin{tabular}{|c|c|c|c|c|}
\hline & \multicolumn{2}{|c|}{ Scaffolders $(n=60)$} & \multicolumn{2}{|c|}{ Supervisors $(n=20)$} \\
\hline & Mean & $S D$ & Mean & $S D$ \\
\hline \multicolumn{5}{|l|}{ Postural load: } \\
\hline $\begin{array}{l}\text { Awkward back posture: bent and twisted over } 45^{\circ \star} \text { ( } \% \text { of } \\
\text { working time) }\end{array}$ & 7.7 & 6.7 & 1.6 & 2.9 \\
\hline One or two arms raised ${ }^{\star}(\%$ of working time $)$ & 27.1 & 14.7 & 2.3 & 3.7 \\
\hline Lifting or carrying loads $>5 \mathrm{~kg}^{\star}$ ( $\%$ of working time) & 22.2 & 8.1 & 0.4 & 0.3 \\
\hline
\end{tabular}

${ }^{\star}$ Student $t$ test and Mann-Whitney $U$ test, $\mathrm{p}<0.05$. 
Table 3 Interrelations among self reported risk factors for low back pain and perceived general health in the study population

\begin{tabular}{llllllll}
\hline Risk factors & 2 & 3 & 4 & 5 & 6 & 7 & 8 \\
\hline 1 & $0.65^{\star}$ & $0.69^{\star}$ & $0.52^{\star}$ & 0.12 & 0.05 & $0.15^{\star}$ & $0.15^{\star}$ \\
2 & - & $0.70^{\star}$ & $0.57^{\star}$ & 0.12 & $0.15^{\star}$ & $0.27^{\star}$ & $0.23^{\star}$ \\
3 & - & - & $0.52^{\star}$ & 0.10 & 0.07 & $0.18^{\star}$ & $0.13^{\star}$ \\
4 & - & - & - & $0.28^{\star}$ & $0.28^{\star}$ & $0.32^{\star}$ & $0.29^{\star}$ \\
5 & - & - & - & - & 0.05 & $0.31^{\star}$ & $0.22^{\star}$ \\
6 & - & - & - & - & - & $0.50^{\star}$ & $0.37^{\star}$ \\
7 & - & - & - & - & - & - & $0.66^{\star}$ \\
\hline
\end{tabular}

«Spearman rank correlation coefficient $\theta, \mathrm{p}<0.05$.

1 Manual handling of materials. 2 Awkward back posture. 3 Strenuous arm positions. 4 Perceived exertion. 5 Job demand. 6 Job control. 7 Need for recovery. 8 Perceived general health.

Table 4 Prevalence of low back pain in the past 12 months among scaffolders and supervisors

\begin{tabular}{lrl}
\hline & $\begin{array}{l}\text { Scaffolders } \\
(n=221) \\
n(\%)\end{array}$ & $\begin{array}{l}\text { Supervisors } \\
(n=66) \\
n(\%)\end{array}$ \\
\hline $\begin{array}{l}\text { Subjects with low back pain } \\
\text { Subjects with chronic low back pain }\end{array}$ & $\begin{aligned} 52(60) \\
\text { Subjects with severe low back pain }\end{aligned}$ & $\begin{array}{l}40(61) \\
13(20)\end{array}$ \\
$\begin{array}{l}\text { Subjects with low back pain and } \\
\text { perceived disability }\end{array}$ & $47(21)$ & $12(18)$ \\
\hline${ }^{\star}$ Cochran-Mantel-Haenszel test, $\mathrm{p}<0.05$. &
\end{tabular}

There was a marked significant difference for high perceived exertion between scaffolders $(72 \%)$ and supervisors $(7 \%)$. Perceived exertion showed an inverted trend for both age $(\mathrm{p}<0.005)$ and total working experience in current company $(\mathrm{p}<0.002)$. The self reported psychosocial load and subjective health was approximately twice as high for scaffolders as for supervisors. High job demand, low job control, need for recovery, and moderate general health differed significantly between the two occupational groups but did not show any significant trend for age or total working experience (table 1).

\section{POSTURAL LOAD}

There was a significant difference in postural load measured at the workplace between scaffolders and supervisors (table 2). In $8 \%$ of working time scaffolders had an awkward back posture in which the back was bent or twisted more than $45^{\circ}$. Supervisors had an awkward back position in almost $2 \%$ of working time. The differences in postural load between the two occupations were even more obvious for raising one or two arms above shoulder level $(27 \%$ of working time for scaffolders versus $2 \%$ for supervisors). According to table 2, supervisors hardly lifted or carried any loads of $5 \mathrm{~kg}$ or more, whereas scaffolders had to carry or lift loads of 5 $\mathrm{kg}$ or more $22.2 \%$ of their work time. On a normal working day a scaffolder lifted at least 5000 $\mathrm{kg}$ of scaffolding materials, and working days were observed with up to $15000 \mathrm{~kg}$ lifted or carried. Due to frequent task rotation within a team of scaffolders, the physical load was not influenced by age or seniority in the job.

INTERRELATIONS OF RISK FACTORS

Table 3 shows the interrelations between self reported risk factors and perceived general health. The correlation coefficients varied considerably (Spearman rank correlation coefficient $\theta=0.04-0.70$ ) but showed a consistent pattern. High and consistent correlation coefficients were found between manual handling of materials, awkward back posture, strenuous arm positions, and perceived exertion $(\theta=0.52-0.70)$. Individual characteristics, such as age, body mass, and job seniority did not affect these interrelations between physical risk factors. No clear associations were found among self reported physical load and psychosocial load $(\theta=0.06-0.14)$. Perceived exertion was related to both job demand and job control $(\theta=0.27)$ but these aspects of psychosocial load were not interrelated. Self reported factors of physical load were associated with both measures of health but these associations were less strong than the correlation between psychosocial factors and these health measures. Not surprisingly, a strong relation was found between the need for recovery and perceived general health $(\theta=0.66)$ but this association was almost absent at older age but stronger with increasing work experience. These reported interrelations among risk factors did not differ between the occupational groups.

END POINTS OF LOW BACK PAIN

Table 4 shows the differences in prevalence of four end points of low back pain between scaffolders and supervisors. Both professions experienced low back pain in the past 12 months; the percentages were almost equal for scaffolders $(58 \%)$ and supervisors $(61 \%)$. The same picture could be drawn for chronic low back pain (scaffolders 23\%, supervisors 19\%) and low back pain with perceived disability (21\% against $19 \%)$. More scaffolders experienced a higher grade of disability than supervisors. The only significant difference between the two professions was found for the subjects who experienced severe low back pain (scaffolders $30 \%$, supervisors $14 \%$ ). There was a difference in medical consumption related to various end points of low back pain. Workers with chronic low back pain in the past 12 months more often sought medical care through their general practitioner $(\mathrm{OR}=2.0)$ and occupational physician $(\mathrm{OR}=3.2)$. These associations were stronger for subjects with severe low back pain with odds ratios of 3.2 and 5.2, respectively. Workers who experienced severe disability at home or at work most often sought medical care with odds ratios of 10.1 and 7.2 , respectively.

In table 5 the univariate analyses for low back pain in the past 12 months adjusted for age are summarised. All risk factors were dichotomised before being entered into the logistic models. All self reported risk factors, except being a scaffolder, were significantly related to the occurrence of low back pain and severe low back pain. Chronic low back pain was not associated with a combination of high job demands and low job control whereas all end points of low back pain were significantly associated with high job demands and none were related to low job control. More specific end points of low back pain showed higher prevalence ratios than the presence of low back pain in the past 12 months. In general, both measures of perceived general health were most strongly associated with the end points of low back pain, especially with chronic and severe low back pain. 
Table 5 Univariate associations between low back pain in past 12 months and self reported risk factors

\begin{tabular}{|c|c|c|c|c|}
\hline Self reported risk factors & $\begin{array}{l}\text { Low back pain } \\
\text { PR }(95 \% \text { CI) }\end{array}$ & $\begin{array}{l}\text { Chronic low back pain } \\
\text { PR }(95 \% \text { CI) }\end{array}$ & $\begin{array}{l}\text { Severe low back pain } \\
P R(95 \% \text { CI })\end{array}$ & $\begin{array}{l}\text { Low back pain and } \\
\text { perceived disability } \\
\text { PR }(95 \% \text { CI) }\end{array}$ \\
\hline Scaffolding & $0.99(0.79$ to 1.25$)$ & $1.21(0.69$ to 2.14$)$ & $2.04(1.13 \text { to } 3.67)^{\star}$ & $1.12(0.61$ to 2.03$)$ \\
\hline High manual handling of materials & $1.35(1.10 \text { to } 1.65)^{\star}$ & $1.43(0.90$ to 2.27$)$ & $1.74(1.15 \text { to } 2.63)^{\star}$ & $1.52(0.93 \text { to } 2.48)^{\star}$ \\
\hline High strenuous arm position & $1.18(0.97 \text { to } 1.44)^{\star}$ & $1.24(0.79$ to 1.96$)$ & $1.41(0.94 \text { to } 2.11)^{\star}$ & $2.17(1.26 \text { to } 3.73)^{\star}$ \\
\hline Many awkward back postures & $1.28(1.06 \text { to } 1.55)^{\star}$ & $1.78(1.14 \text { to } 2.80)^{\star}$ & $1.93(1.30 \text { to } 2.87)^{\star}$ & $1.76(1.10 \text { to } 2.82)^{\star}$ \\
\hline High perceived exertion & $1.28(1.04 \text { to } 1.58)^{\star}$ & $2.39(1.37 \text { to } 4.14)^{\star}$ & $2.10(1.32 \text { to } 3.34)^{\star}$ & $1.82(1.05 \text { to } 3.13)^{\star}$ \\
\hline High job demands & $1.36(1.13 \text { to } 1.64)^{\star}$ & $1.53(0.99 \text { to } 2.37)^{\star}$ & $2.54(1.70 \text { to } 3.78)^{\star}$ & $1.93(1.22 \text { to } 3.06)^{\star}$ \\
\hline $\begin{array}{l}\text { High job demand and low job } \\
\text { control }\end{array}$ & $1.32(1.09 \text { to } 1.58)^{\star}$ & $1.42(0.90$ to 2.24$)$ & $2.32(1.62 \text { to } 3.31)^{\star}$ & $1.55(0.97 \text { to } 2.48)^{\star}$ \\
\hline High need for recovery & $1.45(1.20 \text { to } 1.75)^{\star}$ & $2.30(1.44 \text { to } 3.68)^{\star}$ & $2.49(1.65 \text { to } 3.77)^{\star}$ & $2.06(1.27 \text { to } 3.33)^{\star}$ \\
\hline Moderate perceived general health & $1.47(1.23 \text { to } 1.76)^{\star}$ & $3.00(1.91 \text { to } 4.73)^{\star}$ & $2.99(2.03 \text { to } 4.43)^{\star}$ & $2.54(1.61 \text { to } 4.03)^{\star}$ \\
\hline
\end{tabular}

$\star \chi^{2}$-test, $\mathrm{p}<0.10$.

$\mathrm{PR}=$ prevalence ratio; $95 \% \mathrm{CI}=95 \%$ confidence interval.

Table 6 Multivariate analysis of self reported risk factors and low back pain in past 12 months

\begin{tabular}{|c|c|c|c|c|}
\hline Risk factor & $\begin{array}{l}\text { Low back pain } \\
\text { PR }(95 \% \text { CI) }\end{array}$ & $\begin{array}{l}\text { Chronic low back pain } \\
\text { PR }(95 \% \text { CI })\end{array}$ & $\begin{array}{l}\text { Severe low back pain } \\
\operatorname{PR}(95 \% \mathrm{CI})\end{array}$ & $\begin{array}{l}\text { Low back pain and } \\
\text { perceived disability } \\
\text { PR }(95 \% \text { CI })\end{array}$ \\
\hline \multicolumn{5}{|l|}{ Age } \\
\hline$<35$ & 1.00 & 1.00 & 1.00 & 1.00 \\
\hline $35-44$ & $0.99(0.82$ to 1.20$)$ & $1.31(0.82$ to 2.07$)$ & $1.17(0.80$ to 1.71$)$ & $0.80(0.47$ to 1.36$)$ \\
\hline $45 \geqslant$ & $0.98(0.80$ to 1.19$)$ & $1.37(0.80$ to 2.24$)$ & $1.28(0.82$ to 2.02$)$ & $0.97(0.56$ to 1.68$)$ \\
\hline $\begin{array}{l}\text { High manual handling of } \\
\text { materials }\end{array}$ & $1.28(1.06 \text { to } 1.54)^{\star}$ & NS & NS & NS \\
\hline High strenuous arm positions & NS & NS & NS & $2.05(1.21 \text { to } 3.49)^{\star}$ \\
\hline Many awkward back postures & NS & NS & $1.52(1.03 \text { to } 2.26)^{\star}$ & NS \\
\hline High perceived exertion & NS & $2.05(1.19 \text { to } 3.53)^{\star}$ & NS & NS \\
\hline High job demands & $1.23(1.02 \text { to } 1.47)^{\star}$ & NS & $1.94(1.29 \text { to } 2.92)^{\star}$ & NS \\
\hline High need for recovery & NS & NS & $1.84(1.19 \text { to } 2.83)^{\star}$ & NS \\
\hline $\begin{array}{l}\text { Moderate perceived general } \\
\text { health }\end{array}$ & $1.37(1.14 \text { to } 1.63)^{\star}$ & $2.74(1.74 \text { to } 4.31)^{\star}$ & NS & $2.45(1.56 \text { to } 3.85)^{\star}$ \\
\hline
\end{tabular}

${ }^{\star} \chi^{2}$-test, $\mathrm{p}<0.05$.

$\mathrm{NS}=$ not significant; $\mathrm{PR}=$ prevalence ratio.

The multivariate analyses for the reported risk factors and four different end points of low back pain are shown in table 6. Each classification of low back pain was associated with one physical risk factor with PRs varying from 1.28 to 2.05 , and for one indicator of general health the PRs were between 1.37 and 2.74 . As the four physical factors were strongly interrelated, it was to some extent arbitrary which physical factor proved to be significant. Both health variables were also associated with all end points of low back pain, with perceived general health having a stronger influence than a high need for recovery in the multivariate models. Again, higher measures of association were found for the risk factors and more specific definitions of low back pain. In all four models age, weight, height, work history, occupational group, social support, and high demand combined with low job control did not show any significant relation with the specific end points of low back pain. However, high job demands was the only psychosocial factor that was significantly related to the occurrence of low back pain and severe low back pain. Inclusion of this psychosocial variable in the multivariate models did not influence the observed effect of physical factors but did reduce the influence of the health variables in all four models.

\section{Discussion}

Scaffolders comprise a unique occupational group characterised by heavy physical labour with high levels of force being exerted. A group of 229 scaffolders and 59 supervisors rated their physical and psychosocial load and perceived health by means of a questionnaire.
The data showed that interrelations between these risk factors and various end points of low back pain are diverse and heterogeneous. Aspects of physical load were consistently associated with low back pain, severe low back pain, chronic low back pain, and low back pain with disability. Among the psychosocial risk factors, only high job demands was associated with low back pain and severe low back pain. Self rated general health showed significant relations with all end points of low back pain. As this study has a cross sectional design, the associations presented are merely observed relations and not a cause or a consequence of low back pain.

In this study two different instruments to measure physical load were used: a questionnaire and an instant interval sampling method with many frequent observations. Information from the questionnaire elucidated self reported physical load (table 1) and the instant interval sampling method identified core determinants of physical load (table 2). Although the outcome measures from both instruments are difficult to compare, the results pointed in the same direction. If the postural load of the same scaffolders, who had also filled out the questionnaire, had been assessed by submitting the instant interval sampling method, then the results would have been comparable but this was an enterprise too costly to undertake. However, in our opinion a total number of 9600 observations at the worksite as well as the number of workers observed were sufficient to provide a clear picture of the mean exposure of the study population. ${ }^{19}$ 
According to table 3, the self reported determinants of physical load were highly associated. Interestingly, older and more experienced workers reported lower levels of physical load than their younger colleagues. This could not be explained by differences in tasks and activities related to seniority in the job.

These findings suggest the presence of a healthy worker effect. It is thought by experts that the postural load in scaffolding is the main trigger for health related drop out at older ages. $^{20}{ }^{21}$ Therefore, if older scaffolders are still working they were able to cope and adjust to the demands imposed by the job. Another phenomenon that would support a possible healthy worker effect is the presence of a health related entrance selection. Older scaffolders will not subscribe to a job which is physically demanding if they experience musculoskeletal problems or if their capacity to work does not match the demands of a strenuous job. So either by self selection, selection of the personnel officer, or even by pre-employment medical examination, selection prevents entrance into the job. A third phenomenon in some way related to the healthy worker effect is job promotion from scaffolder to supervisor. Most supervisors had had experience as a scaffolder, and this may partly explain the similar prevalence of low back pain among scaffolders and supervisors.

Psychosocial load showed a weak correlation with physical load but a much stronger correlation with perceived general health. It could be hypothesised that psychosocial load represented by high job demands and low job control plays an important part in the perception of the worker's own health and ability to cope including the need for recovery. In this study, however, this finding seemed to be relatively independent of the physical load applied on the worker. Publications on this point are not conclusive because most studies on psychosocial workload did not adjust for physical load. ${ }^{6}$ In a recent study the authors suggested an interaction between psychosocial and physical risk factors in a working population of which only $24 \%$ experienced high physical exposure. ${ }^{8}$ Our study did not confirm such an interaction.

There is growing evidence that different subgroups of low back pain relate differently to various correlates. ${ }^{22}{ }^{23}$ Therefore, in the univariate analyses of this study calculations were made for four different end points of low back pain of which only one end point was left with an overall significance (table 5). Subsequently, multivariate analyses showed some clear relations between physical risk factors and end points of low back pain (table 6). The relations were less obvious for psychosocial risk factors, whereby only high job demands showed a significant relation with two of the end points. Inclusion of high job demands did not influence the effect of physical risk factors in the multivariate analysis. Thus, in this occupation characterised by heavy physical work the physical load seems to supersede the potential impact of psychosocial load on the occurrence of low back pain. This finding contrasts with information from other studies with presumably lower levels of physical load. ${ }^{84-26}$

Manual handling of materials was significantly related to at least one period of low back pain in the past 12 months. Considering the European definition of manual handling of materials, this relation is what would be expected: manual handling of materials is defined as any transporting or supporting of a load, by one or more workers, including lifting, lowering, pushing, pulling, carrying, or moving of a load, which, by reasons of its characteristics or of unfavorable ergonomic conditions, involves a risk particularly of back injury to workers. ${ }^{27}{ }^{28}$ The resemblance with the occupational characteristics of scaffolders could hardly be more eminent. Ample evidence for the relation between manual handling of materials and low back pain has been presented. One study concluded that the highest exposure to manual handling of materials was found for skilled workers in building frame and construction such as scaffolders. ${ }^{29} \mathrm{~A}$ recent study of occupational risk factors for low back pain in construction workers showed that, among all general construction tasks including manual handling of materials, the highest association was between low back pain and scaffolding. ${ }^{30}$

In our study chronic low back pain was significantly related to perceived exertion. In a study among 148 men who predominantly performed manual work, perceived exertion with or without low back pain was measured. It was concluded that workers with intermittent or chronic low back pain perceived their work as more strenuous. Although the authors in this study used a slightly different definition of chronic low back pain, it indicated the possibility of perceived exertion being a cause and an effect of chronic low back pain. This study also showed that more attention should be given to a person's perception of physical workload. ${ }^{31}$

Low back pain and perceived disability were also significantly related to awkward shoulder positions. Although published evidence is lacking, it could be hypothesised that if low back pain is getting more disabling, the additional load created by the shoulder position, in which the arms are raised almost $30 \%$ of working time (table 2), deteriorates the situation considerably. This might even be more troublesome in the case of shoulder complaints. The same hypothesis might be applicable on the significant relation between severe low back pain and awkward back postures.

Low back pain in the past 12 months $(\mathrm{PR}=1.37,1.14$ to 1.63$)$, low back pain and perceived disability ( $\mathrm{PR}=2.45,1.56$ to 3.85$)$, and especially chronic low back pain $(\mathrm{PR}=2.74,1.74$ to 4.31$)$ were significantly related to poor perceived health. It has been shown that poor health is related to back problems. ${ }^{32}$ From this point of view it is reasonable to expect that poor physical health makes the worker more vulnerable to low back pain when performing heavy physical duties at work. This finding is supported by a study on short term physical risk factors for new episodes of low back pain. The participants in this study were 
derived from a general practice. It was concluded that poor physical health increased the risk of new episodes of back pain in the short term. ${ }^{33}$ But what if the poor health lasted longer and it became a long term risk factor? The findings in table 6 suggest that the risk was not only limited to new episodes of low back pain but that there might be a risk of aggravation and developing low back pain with perceived disability and chronic low back pain.

In conclusion, significant relations were found between self reported risk factors: physical and psychosocial load, and perceived health. Hence, different sets of risk factors were significantly related to various end points of low back pain. Physical load and perceived general health primarily determined the relations with different end points of low back pain. An inverted trend for self reported physical load and age suggested the possible presence of a healthy worker effect. This study showed that assessment of hazardous risk factors might contribute to identifying and recognising their relations with different stages of aggravating low back pain. Additional studies are required in a continued effort to clarify interrelations between risk factors and low back pain as a dynamic entity.

1 Van Tulder MW, Koes BW, Bouter LM. A cost-of illness study of back pain in the Netherlands. Pain 1995;62:23340.

2 Burdorf A, Sorock G. Positive and negative evidence for risk factors of work related back disorders. Scand $\mathcal{F}$ Work Environ Health 1997;23:243-56.

3 Skovron ML. Epidemiology of low back pain. Ballière's Clinical Rheumatology 1992;6:559-73.

4 Hoogendoorn WE, Van Poppel MNM, Bongers PM, et al. Physical load during work and leisure time as risk factor for back pain. Scand $\mathcal{F}$ Work Environ Health 1999;5:387403.

5 Burdorf A, Rossignol MR, Fathallah FA, et al. Challenges in assessing risk factors in epidemiologic studies on back disorders. Am $\mathcal{F}$ Ind Med 1997;32:142-52.

6 Bongers PM, Winter CR, Kompier MAJ, et al. Psychosocial factors at work and musculoskeletal disease. Scand $\mathcal{F}$ Work Environ Health 1993;19:297-312.

7 Dempsey PG, Burdorf A, Webster BS. The influence of personal variables on the work-related low-back disorders and implications for future research. f Occup Environ Med implications for

8 Devereux JJ, Buckle PW, Vlachonikolis IG. Interactions between physical and psychosocial risk factors at work increase the risk of back disorders: an epidemiological approach. Occup Environ Med 1999;56:343-53.

9 Bigos SJ, Battié MC, Spengler DM, et al. A prospective study of work perceptions and psychosocial factor affecting the report of back injury. Spine 1991;16:1-6 10 Riihimäki H. Hands up or back to work-future challenges in f Work Environ Health 1995;21:401-3.
11 Tousignant M, Rossignol M, Goulet L, et al. Occupational disability related to back pain: application of a theoretical model of work disability using prospective cohorts of manual workers. Am f Ind Med 2000;37:410-22.

12 Von Korff M, Ormel J, Keefe FJ, et al. Grading the severity of chronic pain. Pain 1992;50:133-49.

13 Kuorinka I, Jonsson B, Kilbom A, et al. Standard Nordic questionnaires for the analysis of musculoskeletal symptoms. Appl Ergon 1987;18:233-7.

14 Borg G. Psychopsysical scaling with applications in physical work and the perception of exertion. Scand $\mathcal{F}$ Work Environ Health 1990;16(suppl):55-8.

15 Karasek RA, Baker D, Marxer F. Job decision latitude, job demands and cardiovascular disease: a prospective study
among Swedish men. Am f Public Health 1981;71:694-705.

16 Sluiter JK, Van der Beek AJ, Frings-Dresen MHW. The influence of work characteristics on the need for recovery and experienced health: a study on coach drivers. Ergonomics 1999;42:573-83.

17 Van Sonsbeek JLA. De Voeg. A list of subjective health complaints. The Hague: SDU Publishers, 1990. (Statistical reports $M 37$.)

18 Thompson ML, Myers JE, Kriebel D. Prevalence odds ratio or prevalence ratio in the analysis of cross-sectional data: what is to be done. Occup Environ Med 1998;55:272-7.

19 Burdorf A, Van Riel M. Design of strategies to assess lumbar posture during work. International fournal of Industrial Ergonomics 1996;18:239-49.

20 Broersen JPJ, De Zwart BCH, Van Dijk FJH, et al. Health complaints and working conditions experienced in relation to work and age. Occup Environ Med 1996;53:51-7.

21 De Zwart BC, Broersen JP, Van der Beek AJ, et al. Selection related to musculoskeletal complaints among employees. Occup Environ Med 1997;54:800-6.

22 Leboeuf-Yde C, Lauritsen JM, Lauritzen T. Why has the search for causes of low back pain largely been nonconclusive. Spine 1997;22:877-81

23 Ozguler A, Leclerc A, Landre M-F, et al. Individual and occupational determinants of low back pain according to various definitions of low back pain. $\mathcal{F}$ Epidemiol Community Health 2000;54:215-20.

24 Holmström EB, Lindell J, Moritz U. Low back and neck/shoulder pain in construction workers: occupational workload and psychosocial risk factors. Spine 1992;17:66371 .

25 Bildt Thorbjörnsson C, Alfredsson L, Frederiksson K, et al. Physical and psychosocial factors related to low back pain during a 24-year period. A nested case-control analysis. during a 24-year period.

26 Feyer A-M, Herbison P, Williamson AM, et al. The role of physical and psychological factors in occupational low back pain: a prospective cohort study. Occup Environ Med 2000; 57:116-20.

27 Social Europe. Europe for safety and health at work 3/93. Strasbourg: European Commission, 1994:345.

28 Kuiper JI, Burdorf A, Verbeek JHAM, et al. Epidemiologic evidence on manual matrials handling as a risk factor for back disorders: a systematic review. International fournal of Industrial Ergonomics 1999;24:389-404.

29 Heran-Le Roy O, Niedhammer I, Sandret N, et al. Manual materials handling and related occupational hazards: a national survey in France. International fournal of Industrial Ergonomics 1999;24:365-77.

30 Latza U, Karmaus W, Stürmer T, et al. Cohort study of occupational risk factors of low back pain in construction workers. Occup Environ Med 2000;57:28-34.

31 Hultman G, Nordin M, Saraste H. Physical and psychological workload in men with and without low back pain. Scand f Rehabil Med 1995;27:11-17

32 Hurwitz EL, Morgenstern H. Correlates of back problems and back-related disability in the United States. F Clin Epidemiol 1997;50:669-81.

33 Croft PR, Papageorgiou AC, Thomas E, et al. Short-term physical risk factors for new episodes of low back pain. Spine 1999;24:1556-61. 